\title{
Descriptive study of chronic calcific pancreatitis in Sri Lanka
}

\author{
Mohan de Silva ${ }^{1}$, Siva Selliah² and Ira Thabrew ${ }^{2}$ \\ (Index words: Alcoholic and non-alcoholic chronic pancreatitis, malnutrition and consumption of Manihot esculenta)
}

\begin{abstract}
Objectives To describe the potential risk factors, clinical features, biochemical and radiological features, and management of chronic calcific pancreatitis.

Design Cross-sectional descriptive study.

Setting Tertiary care general hospital.

Patients Fifty patients with pancreatic calcification referred to the Colombo South Teaching Hospital, and 50 agematched controls from healthy relatives or friends of the patients.

Measurement Height and weight measurements, immunoreactive insulin levels and trypsin levels of duodenal aspirates were estimated. Plain abdominal xray and ultrasonography were performed.

Intervention Endoscopic retrograde cholangiopancreaticography (ERCP) was attempted on all patients during which duodenal aspirates were collected. Success rates of ERCP and response to endotherapeutic procedures were recorded.
\end{abstract}

Results Twenty two of the 50 chronic calcific pancreatitis (CP) patients were diagnosed to have chronic alcoholic calcific pancreatitis (CACP). Mean age of the CACP patients was significantly higher than that of the chronic calcific pancreatitis of the tropics (CCPT) patients. Severe malnutrition (BMI < 20), frequent consumption of Manihot esculenta (manioc, cassava) and a high consumption of chilli or pepper were identified as possible risk factors for both alcoholic and non-alcoholic CP. Onset of diabetes occurred at a much younger age in the CCPT group than in the CACP group. Mean serum insulin was significantly higher in the CCPT group than in the CACP group and duodenal trypsin level was significantly lower in the CСРT than in CACP group.

Conclusions Our results confirm the existence of both alcoholic (CACP) and non-alcoholic (CCPT) types of chronic calcific pancreatitis in Sri Lanka. A larger study is required to confirm the associated risk factors such as Manihot esculenta and foods with a high content of chilli or pepper.

\section{Introduction}

Chronic pancreatitis (CP) is a disease that can lead to many serious complications such as jaundice, duodenal obstruction, pseudocyst, haemorrhage, diabetes, and cancer of the pancreas $[1,2]$. Presence of pancreatic calculi is a hallmark of chronic pancreatitis [3 ]. Chronic alcohol abuse is the most common cause of chronic calcific pancreatitis in the west $[3,4]$, although only $5-10 \%$ of alcoholics develop CP. This suggests that other factors are important in its pathogenesis [5]. An idiopathic, nonalcoholic form of chronic calcific pancreatitis, referred to as chronic calcific pancreatitis of the tropics (CCPT), has been reported from south India and other tropical and sub-tropical regions of the world [6]. CCPT is the most common cause of $\mathrm{CP}$ in India $[4,7,8]$. CCPT is characterised by recurrent abdominal pain and extensive pancreatic calcification in younger age groups. Genetic predisposition, malnutrition, cyanogenic alkaloids derived from Manihot esculenta and other sources have been implicated as important risk factors associated with the pathogenesis of this condition [9-11]. However, malnutrition and M. esculenta consumption as risk factors for $\mathrm{CP}$ have been questioned $[12,13]$. More recently, mutations of the cystic fibrosis conductance regulator gene (CFRG) have been implicated in CCPT $[14,15]$.

Only limited information is available on the prevalence, sub-types or associated aetiological factors for CP in Sri Lanka [16]. In view of this paucity of information and the conflicting reports regarding potential risk factors associated with CP, a detailed study of CP patients in Sri Lanka becomes important. The objective of the present study was to identify potential risk factors associated with $\mathrm{CP}$, and clinical, biochemical, radiological, and endosonographic features, and success of ERCP and response to endotherapy .

\section{Materials and methods}

Patient selection

All patients with pancreatic calcification referred to the University Surgical Unit in the Colombo South Teaching Hospital , Sri Lanka, between October 2001 and February 2003 were selected for the study. All patients had recurrent abdominal pain suggestive of $\mathrm{CP}$ and pancreatic calcification as evident from xray and confirmed by ultrasonography. There was no upper age limit. A detailed history, physical examination, serum insulin levels, trypsin levels of duodenal aspirates, plain xray of the abdomen and ultrasonography were obtained. Patients who had clinical features suggestive of chronic pancreatitis without radiological evidence of pancreatic calcification, gallstone disease, and children

${ }^{1}$ Faculty of Medical Sciences, University of Sri Jayawardenepura, Nugegoda, Sri Lanka. ${ }^{2}$ Faculty of Medicine, University of Kelaniya, Talagolla Road, Ragama, Sri Lanka.

Correspondence: M de S, e-mail: <thathya@stmail.Ik> (Competing interests: none declared). Received 7 September 2004 and accepted 24 September 2004. 
below the age of 10 years were excluded from the study. Controls were selected from healthy relatives and friends of patients and age matched to the cases. Approval for the study was granted by the ethical committee of the University of Sri Jayawardenepura, Sri Lanka.

\section{Data collection}

A structured questionnaire and face-to-face interview were employed to collect patient data. The questionnaire was designed to collect information on socio-demographic factors such as gender, age, occupation, past history, and family history. The consumption patterns of Manihot esculenta which contains cyanogenic glucosides, spicy food, chilli, pepper, alcohol, tea and coffee were also recorded. Height and weight of each individual was measured according to standard criteria.

Clinical data regarding the onset, duration and severity of abdominal pain were recorded. Serum insulin levels and trypsin levels in duodenal aspirates collected during ERCP were estimated to assess pancreatic function in selected patients. Information about the radiological features of the pancreas in the selected CP patients was obtained by xray and ultrasonography. All patients selected for the study were subjected to ERCP. Those patients who had dilated pancreatic duct at ERCP, underwent selective pancreatic duct sphincterotomy, stricture dilation, stone extraction and stenting of the pancreatic duct. Response to endotherapy at 6 months was assessed and recorded.

\section{Biochemical estimations}

Immunoreactive insulin was estimated using the IMx-insulin assay. The insulin assay was based on the microparticle enzyme immunoassay technology. Pancreatic exocrine function was assessed by estimation of trypsin levels in duodenal aspirates by the colorimetric method of Gowenlock, as described by Varley [19]

\section{Radiological assessment}

Plain abdominal radiographs were obtained to detect calcification in the region of the pancreas. Ultrasonography was performed. Contour and size of the pancreas, echogenicity of parenchyma, ductal size and contour, and the type of calculi were recorded.

\section{Statistical analysis of data}

Parametric methods $\chi^{2}$ and t-test were used to compare data between the groups, and also to examine correlations between different variables.

\section{Results}

\section{Aetiological risk factors}

Demographic data of patients and controls are summarised in Table 1. Of the 50 patients in the test group, there were 28 patients with no history of alcohol intake; and these patients hence are classified as the CCPT group. Twenty two patients who admitted consuming alcohol regularly (at least $50 \mathrm{~g}$ alcohol / day for a minimum of 5 years before the onset of symptoms associated with $\mathrm{CP}$ ) were considered as the chronic alcoholic calcific pancreatitis (CACP) group [4]. As these were clinically distinct groups, the results were compared between the two groups during data analysis.

As seen in Table 1, the mean age of patients in the CACP group $(43.7 \pm 8.9)$ was significantly higher $(\mathrm{p}<0.05)$ than that of the CCPT group $(34.7 \pm 10)$. This observation supports findings of previous researchers $[4,7]$. In keeping with the observations of Chari et al. [4] in India and of Rajasuriya in Sri Lanka [16], in this study too, CACP was seen exclusively among males, compared to CCPT (male : female ratio $4.5: 1$ ).

No significant differences were observed in the mean weights between the two groups. The percentage of patients with body mass index $(\mathrm{BMI})<20$ was also similar in the two groups $(72 \%)$. The proportion of severely malnourished individuals (BMI $<20)$ in the test group was significantly higher $(\mathrm{p}<0.05)$ than in the control group (35\%). The percentage with a monthly income of less than Rs 5000/- was higher in the CACP group (94\%) compared to the CCPT group (65\%); the percentage in the CCPT group with this monthly income was similar to that of the control group (58\%).

The frequency of cigarette smoking, consumption of chilli, hot foods and intake of tea or coffee in the two groups and controls are shown in Table 2. No significant differences were seen in smoking and tea or coffee consumption. However, when compared to the controls, the consumption of chilli and black pepper were significantly $(\mathrm{p}<0.05)$ higher in the two patient groups. Between the two groups, the consumption of chilli and black pepper was higher in the CACP group than in the CCPT group.

Frequent consumption of $M$. esculenta appeared to be related to an increased risk of chronic calcific pancreatitis. In the CACP group $45.5 \%$, and in the CCPT group $35.7 \%$, indicated that they consumed it at least once a week during the past 5 years. In the control group of 50 individuals without pancreatitis, the weekly frequency of manioc consumption was only $4 \%$. Although the sample size is too small for a definitive conclusion, the present data suggests that a high consumption of $M$. esculenta is likely to be a risk factor for the development of chronic calcific pancreatitis.

\section{Clinical features}

The commonest clinical presentation in both groups of $\mathrm{CP}$ patients was abdominal pain radiating to the back. Pain was aggravated by fatty foods in $64.3 \%$. The onset of pain was before 40 years of age in all CCPT patients. In the CACP group, $50 \%$ developed the pain only after the age of 50. The pain was more severe in the CCPT patients and $80 \%$ of these patients had pain scores of 7 or more on a visual analog scale. Such severe pain was observed in only $54.5 \%$ of CACP patients. Although the severity 
of pain differed, $84 \%$ of patients in both the groups were on oral narcotic analgesics for pain relief at the time of presentation.

\section{Biochemical findings}

The mean serum insulin level was, however significantly $(\mathrm{p}<0.05)$ higher in the CCPT group than in

Table 1. Demographic data of patients with chronic calcific pancreatitis

\begin{tabular}{|c|c|c|c|}
\hline & $\begin{array}{c}\text { Alcoholic } \\
(C A C P)\end{array}$ & $\begin{array}{c}\text { Non-alcoholic } \\
(C C P T)\end{array}$ & Control \\
\hline Number & 22 & 28 & 50 \\
\hline Mean age & $43.7 \pm 8.9$ & $34.7 \pm 10$ & $52 \pm 8$ \\
\hline Male:female & 18:0 & $4.5: 1$ & $9: 1$ \\
\hline Domicile: Urban & $55.5 \%$ & $36.4 \%$ & $52.5 \%$ \\
\hline Rural & $44.5 \%$ & $63.6 \%$ & $48 \%$ \\
\hline Mean body weight(kg) & $46 \pm 9.8$ & $48.3 \pm 10.5$ & $49.2 \pm 10.2$ \\
\hline BMI $\left(\mathrm{kg} / \mathrm{m}^{2}\right)<20$ & $72.2 \%$ & $72.5 \%$ & $35 \%$ \\
\hline $20-25$ & $27.8 \%$ & $27.3 \%$ & \\
\hline$>25$ & 0 & 0 & \\
\hline \multicolumn{4}{|l|}{ History of diabetes } \\
\hline Yes & $21.9 \%$ & $42.9 \%$ & \\
\hline No & $78.10 \%$ & $57.1 \%$ & \\
\hline Family history of chronic pancreatitis & none & none & \\
\hline Education up to ' $\mathrm{O}$ ' level standard & $66.7 \%$ & $81.9 \%$ & $55.2 \%$ \\
\hline \multicolumn{4}{|l|}{ Occupation } \\
\hline Non-professional & $94.0 \%$ & $65 \%$ & $58 \%$ \\
\hline Professionals & $5 \%$ & $15 \%$ & $7 \%$ \\
\hline Others & $6.0 \%$ & $20 \%$ & $35 \%$ \\
\hline
\end{tabular}

BMI-body mass index, CACP-chronic alcoholic calcific pancreatitis, CCPT-chronic calcific pancreatitis of the tropics

Table 2. Frequency distribution of smoking, chilli consumption and tea / coffee intake in alcoholic and non-alcoholic chronic pancreatitis patients

\begin{tabular}{|c|c|c|c|}
\hline & $\begin{array}{l}C A C P \\
(n=22)\end{array}$ & $\begin{array}{l}C C P T \\
(n=28)\end{array}$ & $\begin{array}{c}\text { Control } \\
(n=50)\end{array}$ \\
\hline \multicolumn{4}{|l|}{ Smoking } \\
\hline Yes & $18(81.8 \%)$ & $9(32.1 \%)$ & $22(44 \%)$ \\
\hline No & $4(18.2 \%)$ & $19(67.9 \%)$ & $28(56 \%)$ \\
\hline \multicolumn{4}{|c|}{ Cigarettes/week } \\
\hline $1-9$ & $4(22.2 \%)$ & $2(22.2 \%)$ & \\
\hline $10-19$ & $2(11.1 \%)$ & $3(33.3 \%)$ & \\
\hline$>20$ & $12(66.7 \%)$ & $4(44.5 \%)$ & \\
\hline \multicolumn{4}{|c|}{ Daily tea consumption } \\
\hline Yes & $22(100 \%)$ & $28(100 \%)$ & $3(86.0 \%)$ \\
\hline No & 0 & 0 & 7 \\
\hline \multicolumn{4}{|c|}{ Daily coffee consumption } \\
\hline Yes & $7(31.8 \%)$ & $2(7.2 \%)$ & $14(28 \%)$ \\
\hline No & $15(68.2 \%)$ & $26(92.8 \%)$ & $36(72 \%)$ \\
\hline \multicolumn{4}{|c|}{ Daily intake of highly spiced foods } \\
\hline Yes & $21(94.4 \%)$ & $20(71.4 \%)$ & $21(42.0 \%)$ \\
\hline No & $1(5.6 \%)$ & $8(28.3 \%)$ & $29(58 \%)$ \\
\hline \multicolumn{4}{|c|}{ Daily red chilli consumption } \\
\hline & $19(88.3 \%)$ & $19(67.8 \%)$ & $16(32 \%)$ \\
\hline \multicolumn{4}{|c|}{ Daily green chilli consumption } \\
\hline & $14(63.6 \%)$ & $13(46.4 \%)$ & $14(28.0 \%)$ \\
\hline \multicolumn{4}{|c|}{ Daily kochi (hot) chilli consumption } \\
\hline \multicolumn{4}{|c|}{ Daily pepper consumption } \\
\hline
\end{tabular}

CACP-chronic alcoholic calcific pancreatitis, CCPT-chronic calcific pancreatitis of the tropics 
the CACP group (Table 3). The duodenal trypsin level, although close to the lower limit of normal (1520 units ), was significantly $(\mathrm{p}<0.01)$ lower in CCPT when compared to CACP.

Table 3. Biochemical features of CACP and CCPT in Sri Lanka

\begin{tabular}{|c|c|c|}
\hline & $\begin{array}{l}C A C P \\
(n=28)\end{array}$ & $\begin{array}{l}C C P T \\
(n=22)\end{array}$ \\
\hline Serum insulin $(\mathrm{U} / \mathrm{mL})$ & $10.4 \pm 2.5$ & $15.4 \pm 3.4$ \\
\hline Duodenal trypsin (units) & $1111 \pm 292$ & $515.9 \pm 169$ \\
\hline
\end{tabular}

CACP-chronic alcoholic calcific pancreatitis,

CCPT-chronic calcific pancreatitis of the tropics

\section{Radiological features}

As shown in Table 4, radiological findings in the two groups of $\mathrm{CP}$ patients showed striking differences. While speckled calcification was the main feature in the CACP group (71.4\% of CACP vs $39.6 \%$ of CCPT), a high percentage of patients with CCPT had coarse calcium plaques distributed in the more central parts of the glands ( $85 \%$ of CCPT vs $12 \%$ of CACP). Similar observations have been reported in Indian studies [4, 20].

Table 4. Comparison of radiological appearance of pancreatic calcification in CACP and CCPT

\begin{tabular}{lcc}
\hline & $\begin{array}{c}\text { Alcoholic } \\
(C A C P) \\
(n=22)\end{array}$ & $\begin{array}{c}\text { Non-alcoholic } \\
(C C P T) \\
(n=28)\end{array}$ \\
\hline $\begin{array}{l}\text { Distribution of calculi (\%) } \\
\text { Right and left of lumbar }\end{array}$ & 68 & 76 \\
vertebrae & & \\
$\quad \begin{array}{l}\text { Right of vertebrae } \\
\text { Left of vertebrae }\end{array}$ & 24 & 10 \\
$\begin{array}{l}\text { Shape and margins of } \\
\text { calculi (\%) } \\
\text { Well defined margins }\end{array}$ & 6.4 & 12 \\
$\quad$ Speckled and irregular & 12 & 85 \\
\hline CACP- & 71.4 & 36.6 \\
\hline
\end{tabular}

CACP-chronic alcoholic calcific pancreatitis,

CCPT-chronic calcific pancreatitis of the tropics

\section{Diabetes mellitus}

At the time of presentation, $64.8 \%$ of the total sample of patients had diabetes mellitus. The prevalence of diabetes was higher in the CCPT group than in the CACP group $(21.9 \%$ in CACP vs $42.9 \%$ in CCPT ). The onset of diabetes also occurred at a younger age in CCPT $(34 \pm$ 5.0 years) than in CACP ( $40 \pm 3.5$ years $)$.

\section{Endoscopic retrograde cholangiopancreaticogram}

Ultrasonography and ERCP findings in the two groups are shown in Table 5. ERCP was successful in $70 \%$ of the patients $(n=35)$. Of these, $17(77.3 \%)$ were in the CACP group . Cannulation was less successful in CCPT; the success rate was $64.3 \%$.
Table 5. Comparison of ultrasonographic and ERCP findings in CACP and CCPT

\begin{tabular}{lccccc}
\hline & $\begin{array}{c}\text { Alcoholic }(C A C P) \\
(n=22)\end{array}$ & & $\begin{array}{c}\text { Non-alcoholic } \\
(\mathrm{n}=28)\end{array}$ & \\
\cline { 2 - 3 } \cline { 5 - 6 } & $\begin{array}{c}\text { Ultrasound } \\
(n=22\end{array}$ & $\begin{array}{c}\text { ERCP } \\
(n=17)\end{array}$ & $\begin{array}{c}\text { Ultrasound } \\
(n=28)\end{array}$ & $\begin{array}{c}\text { ERCP } \\
(n=18)\end{array}$ \\
\hline Duct dilation & 22 & 13 & & 28 & 17 \\
Duct calculi & 12 & 8 & & 18 & 14 \\
Stricture & 0 & 4 & 0 & 4 \\
\hline
\end{tabular}

Numbers indicate the number of patients studied. CACP-chronic alcoholic calcific pancreatitis, CCPT-chronic calcific pancreatitis of the tropics, ERCP-endoscopic retrograde cholangiopancreaticography

\section{Endotherapy}

As shown in Table 6,17 stents were placed after selective pancreatic duct sphincterotomy. Of these, 10 were in the CACP group and seven in the CCPT group. Proximal duct strictures were dilated in four patients and pancreatic stones were extracted in three CCPT patients. Of the patients who underwent pancreatic duct stenting,

Table 6. Comparison of endotherapy in CACP and CCPT

\begin{tabular}{cc}
\hline Alcoholic & Non-alcoholic \\
$($ CACP $)$ & $(C C P T)$ \\
$E R C P$ & $E R C P$ \\
$(n=17)$ & $(n=18)$ \\
\hline
\end{tabular}

Selective pancreatic

duct

Sphincterotomy

Stricture dilatation

$16 \quad 18$

Stone extraction

Pancreatic duct stenting

Pain relief at 6 months

2

$\begin{array}{ll}2 & 3 \\ 0 & 3\end{array}$

$10 \quad 7$

(Not on narcotic analgesics)

Numbers indicate the number of patients studied. $\mathrm{CACP}-$ chronic alcoholic calcific pancreatitis, CCPT-chronic calcific pancreatitis of the tropics, $\mathrm{ERCP}-$ endoscopic retrograde cholangiopancreaticography

$50 \%$ of the CCPT patients and $54 \%$ of the CACP patients were found to have stopped narcotic analgesics when they were reviewed at the 6 month follow up clinic.

\section{Discussion}

Chronic pancreatitis has been reported from several tropical countries [12,21-23]. Results of a study conducted in 1970, ( with 35 patients), suggested alcoholism and protein energy malnutrition as two possible causative factors of CP [16]. However, there is no definitive information regarding the prevalence of $\mathrm{CACP}$ and $\mathrm{CCPT}$ or the associated risk factors in Sri Lanka.

Results of the present study confirm the existence of both alcoholic (CACP) and non-alcoholic (CCPT) 
chronic calcific pancreatitis patients. A comparison of findings in the CACP and CCPT patients reveals some interesting features, some of which are new and some are well established.

As reported in India [4], the profile of CCPT in Sri Lanka also appears to be different from that reported by earlier researchers. According to these reports, pain in the abdomen in childhood, diabetes at puberty, and death at the prime of life describes the natural history of CCPT. The CCPT patients in the present study, like those from the more recent studies in India [4] appear to be much older than those reported in the earlier studies. The mean age of $34.7 \pm 10$ years in CCPT patients at presentation in the present study is similar to those reported in Indian studies [4,7]. Early onset and increased severity of pain observed in the present study in CCPT patients, when compared with the CACP patients, confirms the early presentation and rapid progress of the disease in CCPT compared to CACP, as observed in studies in India. This view is supported by the relatively higher serum insulin and lower duodenal trypsin levels in the CCPT group of patients when compared with the CACP group. The percentage of patients with diabetes mellitus at presentation was also higher in the CCPT group than in the CACP group as observed by other investigators in India and the west [24].

A genetic predisposition is believed to play a role in the development of CCPT [22]. However, none of the patients in the present study had a family history of diabetes or pancreatic disease.

In the present study, severe malnutrition $(\mathrm{BMI}<20)$, frequent consumption of $M$. esculenta and a high consumption of chilli or pepper have been identified as factors associated with both types of $\mathrm{CP}$, although consumption appears to be marginally higher for the CACP than the CCPT group.

Many investigations have been conducted to analyse the relationship between malnutrition and pancreatic calcification. Early studies on calcific pancreatitis have postulated protein malnutrition as a possible aetiological factor in the development of CCPT [4,10,25], although some researchers are not convinced about malnutrition being a risk factor $[12,13]$.

Results of the present investigation support the view that malnutrition (as indicated by BMI $<20$ ) is a risk factor, although it appears to be equally important for both the alcoholic and the non-alcoholic forms of CP, as demonstrated in the study in Kerala [4]. The view that malnutrition is an important risk factor for chronic calcific pancreatitis is open to debate as the deficiency of digestive enzymes in this condition could lead to a state of malnutrition and malnutrition may be its effect rather than the cause.

Some investigators [4] believe that the risk of CCPT is high with frequent consumption of M. esculenta, although others $[11,13]$ do not agree. Dietary deficiency of sulphur amino acids could hamper detoxification of cyanide from $M$. esculenta to thiocyanate and lead to high levels of free cyanide that are toxic to $\beta$-cells of the pancreas [25]. Concomitant exposure to alcohol and cyanide in cigarette smoke may lead to alcoholic chronic calcific pancreatitis [10]. In our study, no significant relationship was found between cigarette smoking and CACP or CCPT Further studies with a larger sample of patients will be needed to arrive at a more definite conclusion regarding the extent to which $M$. esculenta consumption is a risk factor for CACP and CCPT in Sri Lanka.

An ultrasonographic evaluation of the pancreas in CCPT patients in India has shown the pancreas to be shrunken and fibrosed with a dilated pancreatic duct and intraductal calculi. Similar observations were made in our study. Thus, in the highly selected sample of symptomatic patients with pancreatic calcification in our study, ERCP was less successful in the CCPT patients, probably because of the extensive fibrosis and calcium depositions that caused deformity of the gland and pancreatic duct strictures. However, once the access to the pancreatic duct was obtained to perform endotherapy, the response to treatment between the two groups at 6 months did not show a significant difference.

\section{Conclusions}

Results confirm the existence of both alcoholic (CACP) and non-alcoholic (CCPT) types of chronic calcific pancreatitis patients in Sri Lanka. Patients with CCPT presented at a younger age than those with CACP but appear to be older than those reported in earlier studies. Early onset of pain and exocrine dysfunction was observed in patients with CCPT. The percentage of patients with diabetes mellitus at presentation was higher in the CCPT group. Large discrete calculi were the characteristic radiological appearance in CCPT patients, and speckled calcific plaques were frequently observed in CACP. Endotherapeutic procedures were less successful in CCPT, although the response to endotherapy was similar in the two groups. A larger study is required to confirm the possible associated risk factors such as M. esculenta and foods with high content of chilli or pepper

\section{Acknowledgements}

The authors thank the National Science Foundation of Sri Lanka for the research grant (grant number RG/ 2001/M/05), Dr. N Somaweera, Radiologist, and Mr. S Keerthiseana and Mr. AG Perera for technical assistance. We also thank Dr. P Sudharshan for his assistance in collecting information for the questionnaire.

\section{References}

1. Gold EB and Cameron JL. Chronic pancreatitis and pancreatic cancer. New England Journal of Medicine 1993; 328: $1485-6$. 
2. Hansen TH, Laursen M,Christensen E, Worning $\mathrm{H}$. Chronic pancreatitis and extrapancreatic cancer: a retrospective study among 181 patients with chronic pancreatitis. International Journal of Pancreatology 1995; 18: 235-9.

3. Sarles H, Sahel J, Staub JL, Bourry J, Laugier R. The Exocrine Pancreas: Chronic Pancreatitis. London: Saunders, 1979.

4. Chari ST, Mohan V, Jayanthi V, Snehalatha C, Malathi S, et al. Comparative study of the clinical profiles of alcoholic chronic pancreatitis and tropical chronic pancreatitis in Tamil Nadu, South India. Pancreas 1992; 7: 52-8.

5. Bisceglie AM, Segal I. Cirrhosis and chronic pancreatitis in alcoholics. Journal of Clinical Gastroenterology 1984; 6: 199-201.

6. Shaper AG. Chronic pancreatitis disease and protein malnutrition. Lancet 1960; 2: 1223-4.

7. Balaji LN, Tandon RK, Tandon BN, Banks PA. Prevalence and clinical features of chronic pancreatitis in southern India. International Journal of Pancreatology 1994; 15: 29-34.

8. Sidhu SS, Shah P, Prasanna BM, Srikanta SS, Tandon RK. Chronic calcific pancreatitis of the tropics (CCPT): spectrum and correlates of exocrine and endocrine pancreatic dysfunction. Diabetes Research and Clinical Practice 1995; 27: 127-32.

9. Nwakolo C, Oli J. Pathogenesis of juvenile tropical pancreatitis syndrome. Lancet 1998; 1: 456-9.

10. Pitchumoni.CS, Jain NK, Lowenfels AB, DiMagno EP. Chronic cyanide poisoning: unifying concept for alcoholic and tropical pancreatitis. Pancreas 1988; 3: 220-2.

11. Narendranath M, Cheriyan A. Lack of association between cassava consumption and tropical pancreatitis syndrome. Journal of. Gastroenterology and Hepatology 1994; 9: $282-5$

12. Balakrishnan V, Sauniere J.F, Hariharan M, Sarles H. Diet, pancreatic function and chronic pancreatitis in South India and France. Pancreas 1988; 3: 30-5.

13. Vannasaeng S, Nitiyanant W, Vichayanrat A. Case control study on risk factors associated with fibrocalculus pancreatic diabetes. Diabetic Medicine 1998; 5: 835-9.
14. Cohn JA, Friedman KJ, Noone PG, Knowles MR, Silvermam LM, et al. Relation between mutations of the cystic fibrosis gene and idiopathic pancreatitis. New England Journal of Medicine 1998; 339: 653-8.

15. Noone PG, Zhon Z, Silverman LM, Jowell PS, Knowles MR, Cohn JA. Cystic fibrosis gene mutations and pancreatitis risk: Relation to epithelial ion transport and trypsin inhibitor gene mutations. Gastroenterology 2001; 121: 1310-19.

16. Rajasuriya K. Pancreatic calcification in Ceylon with special reference to its aetiology. Ceylon Medical Journal $1970 ; 1-24$.

17. Augustine $\mathrm{P}$, Ramesh $\mathrm{H}$. Is tropical pancreatitis premalignant? American Journal of Gastroenterology 1992; 87: 1005-8.

18. Chari ST, Mohan V, Pitchumoni CS, Viswanathan M, Madanagopalan N, Lowenfels AB. Risk of pancreatic carcinoma in tropical calcifying pancreatitis and epidemiological study. Pancreas 1994; 9: 62-6.

19. Varley H. Practical Clinical Biochemistr:y, 4th ed. India: CBS Publishers, 1998: 396-397.

20. Mohan V., Chari ST, Hitman GA, Suresh S, Madanagopalan $\mathrm{N}$, et al. Familial aggregation in tropical fibrocalculous pancreatic diabetes. Pancreas 1989; 4: 690-3.

21. Balakrishnan V. Chronic calcific pancreatitis in the tropics. Indian Journal of Gastroenterology 1984; 3: 65-7.

22. Mohan V, Chari S, Viswanathan M, Madanagopalan N. Tropical calcific pancreatitis in southern India Proceedings Royal College of Physicians Edinburgh. 1990, 20: 34-42.

23. Segal I, Lerios M, MacPhail AP, di Bisceglie AM, Grieve TP. The genesis of chronic pancreatitis in the South African black population. South Afrrican Medical Journal 1988; 74: 385-6.

24. Mohan V, Snehalatha C, Chari ST, Bhattacharyya PK, Madanagopalan N et al. Clinical and Biochemical studies in the prediabetic phase of tropical calcific pancreatitis. Pancreas 1992; 1: 109-3.

25. McMillan DE, Geevarghese PJ. Dietary cyanide and tropical malnutrition diabetes. Diabetes. Care 1979; 2: $202-8$. 